\title{
REDES DE POLÍTICAS Y MEDIACIÓN TERRITORIAL EN EL ÁMBITO DE INTERVENCIÓN PARA LA AGRICULTURA FAMILIAR EN ARGENTINA. CASOS EN LA PROVINCIA DE MISIONES ${ }^{1}$
}

\author{
Mariana Arzeno (*) \\ Gabriela Álvarez $(\cdot \bullet)$ \\ Instituto de Geografía, \\ Universidad de Buenos Aires / CONICET
}

\section{RESUMEN}

El presente trabajo analiza las políticas públicas para la agricultura familiar (AF) y la seguridad/soberanía alimentaria (SSA) que se implementaron en la provincia de Misiones (y específicamente en los municipios de Comandante Andresito y Bernardo de Irigoyen), en el contexto de discusión, elaboración e implementación de tales políticas en Argentina entre 2003 y 2015 . El trabajo empírico se sustenta en el relevamiento, sistematización y análisis de información secundaria y primaria obtenida en trabajos de campo realizados en la provincia entre los años 2012 y 2015 . A través de la indagación en las redes de políticas y mediación territorial como estrategia teórico-metodológica, el análisis muestra que existen contradicciones entre los diversos niveles y órganos de intervención y una pluralidad de ideas y estrategias concretas para intervenir en torno a la problemática de la AF y el logro de la SSA, visibilizando cómo entran a jugar los actores locales y las relaciones de poder entre ellos en la orientación predominante que toman las políticas.

PALABRAS CLAVE:

políticas públicas, agricultura familiar, seguridad y soberanía alimentaria, redes de políticas, territorio.

RECEPCIÓN: 27/12/16

ACEPTACIÓN FINAL: 15/09/17

\footnotetext{
(•)E-mail: mariana.arzeno@conicet.gov.ar

(••) E-mail: gabriela.alvarez.gigena@gmail.com
}

69 